\title{
Innovation in a complex environment
}

\author{
Author: \\ René Pellissier ${ }^{1}$ \\ Affiliation: \\ ${ }^{1}$ Department of Business \\ Management, University of \\ South Africa, South Africa \\ Correspondence to: \\ René Pellissier \\ Email: \\ pellir@unisa.ac.za \\ Postal address: \\ PO Box 392, UNISA 0003, \\ South Africa \\ Dates: \\ Received: 27 Aug. 2011 \\ Accepted: 28 Aug. 2012 \\ Published: 28 Nov. 2012 \\ How to cite this article: \\ Pellissier, R., 2012, \\ 'Innovation in a complex \\ environment', SA Journal of \\ Information Management \\ 14(1), Art. \#499, 14 pages. \\ http://dx.doi.org/10.4102/ \\ sajim.v14i1.499
}

C) 2012. The Authors. Licensee: AOSIS OpenJournals. This work is licensed under the Creative Commons Attribution License.
Background: As our world becomes more global and competitive yet less predictable, the focus seems to be increasingly on looking to innovation activities to remain competitive. Although there is little doubt that a nation's competitiveness is embedded in its innovativeness, the complex environment should not be ignored. Complexity is not accounted for in balance sheets or reported in reports; it becomes entrenched in every activity in the organisation. Innovation takes many forms and comes in different shapes.

Objectives: The study objectives were, firstly, to establish the determinants for complexity and how these can be addressed from a design point of view in order to ensure innovation success and, secondly, to determine how this changes innovation forms and applications.

Method: Two approaches were offered to deal with a complex environment - one allowing for complexity for organisational innovation and the other introducing reductionism to minimise complexity. These approaches were examined in a qualitative study involving case studies, open-ended interviews and content analysis between seven developing economy (South African) organisations and seven developed economy (US) organisations.

Results: This study presented a proposed framework for (organisational) innovation in a complex environment versus a framework that minimises complexity. The comparative organisational analysis demonstrated the importance of initiating organisational innovation to address internal and external complexity, with the focus being on the leadership actions, their selected operating models and resultant organisational innovations designs, rather than on technological innovations.

Conclusion: This study cautioned the preference for technological innovation within organisations and suggested alternative innovation forms (such as organisational and management innovation) be used to remain competitive in a complex environment.

\section{Introduction}

\section{A complex environment}

The modern world has been inundated by catastrophic events that change the business and social environment and break society's confidence in stability. In addition, there seems to be new challenges for the 21st century. Meieran's (2012) lists of 20th century innovation issues include: water supplies, the automobile, electricity and air transportation. In contrast, he believes innovation issues for the 21st century include food and water production, resource protection and energy conservation. The Center for Strategic and International Studies (2012) identify seven revolutions for the 21st century, (1) population (growth, aging, migration and urbanisation), (2) resource management (food, water, energy and climate), (3) technology (computation, robotics, biotechnology and nanotechnology), (4) information (data growth, access or privacy, education), (5) economics (global integration, new players, debt, poverty and inequality), (6) security (new security dynamics, health and cyber security) and (7) governance (civil society and non-profit organisations, multilaterals and the future outlook).

The on-going worldwide financial crisis highlights the sensitivity and interrelatedness of businesses. It also hints at developing economies being more inclined to accept change in crises (even to live in uncertainty and instability) than developed economies because of their inherent capacity to deal with ongoing discontinuous change. Developing economies, especially, are more prone to the implementation of non-linear solutions because of the nature of the variables, the changes and interplays between the variables, the significant human foci and the consequent organic nature of competitiveness. These variables introduce an unavoidable element of unpredictability or randomness into any science that can be accommodated by a complex solution. Complexity management allows for pattern recognition which requires focusing on competencies, activities, technologies or resources signalling patterns that will have a positive or negative impact on strategy or operations. 
A complex theory possibly provides the only platform for stability in an otherwise unruly and dynamic world. Complexity principles could replace the mechanistic ones based on a well-behaved universe. This article explores the effect of complexity (external and internal to the organisation) on organisational innovation and design. In this regard, three determinant questions should be asked:

1. 'What are the determinants for complexity in the business environment?'

2. 'How can these be addressed from a design point of view to ensure innovation success?'

3. 'How will that change innovation forms and applications?'

The research design is qualitative as the research focuses on emergent phenomena; that is, the emergence of complexity science in the innovation domain. Interviews were conducted with a selection of chief executive officers (CEOs) in developed and developing economies to determine the extent of organisational innovation in each.

Business as a complex system requires the acknowledgement that we cannot control organisations to the degree that a mechanistic perspective will. Moreover, as the system's environment changes, so does the behaviour of its agents. Thus, the behaviour of the system as a whole can change. Linear strategies and technologies become irrelevant with a shift to patterns and relationships between entities.

\section{Reasons for organisational innovation in a complex environment \\ Taylorism}

Existing management theory is embedded in the four primary functions: planning, organising, leading and controlling. It presupposes a linear approach where inputs and outputs are related and productivity occurs when outputs are bigger than inputs, in line with Newton's three laws of motion. In 1911, Scientific Management entered the scene with Taylor's four principles (in Fayol 1987), namely, (1) replacing ruleof-thumb work methods with methods based on a scientific study of the different tasks to be done, (2) scientifically selecting, training and developing each employee rather than passively leaving them to train themselves, (3) providing detailed instruction and supervision of each worker in the performance of that worker's discrete task and (4) dividing work equally between managers and workers, so that the managers apply scientific management principles to planning the work and the workers actually perform the tasks. Taylor insisted that it is only through, (1) enforced standardisation of methods, (2) enforced adoption of the best implements and working conditions and (3) enforced cooperation that this faster work can be assured. He felt that the duty of enforcing the adoption of standards and enforcing this cooperation rests with management alone (Fayol 1987). From this definitive management paradigm more 'scientific' control became the norm enabling the mass-production revolution to benefit mainly the new elite (e.g. black Ford motor cars around 1920).

\section{Technology change and a new science}

Technology is changing at an unprecedented rate and we often find ourselves adrift amidst resultant discontinuous change. There is no luxury of anticipating and planning for change; rather, as Stephen Hawking (in Porter-O'Grady \& Malloch 2003:36), states, 'change is'. Instead of being guided by a set of concrete principles, management in the 21 st century must be fluid and adaptable to keep pace with changing conditions (Porter-O'Grady \& Malloch 2003). In the 20th century, organisations focused on finding and performing the right processes; whereas, in the 21st century, the focus is on delivering the desired outcomes (Porter-O'Grady \& Malloch 2003). The process (or work) itself does not guarantee that the intended outcome will be achieved. Our understanding of the future changes on a daily basis and some would argue that the future is, in fact, unknowable (Stacey, Griffin \& Shaw 2000). In 21st century organisations, relationships between people inside organisations are the domain and work of leadership, rather than movement toward some preselected organisational goal or benchmark. In order to thrive amidst the unknown, leadership must embrace new ways of being and interacting (Hamalainen \& Saarinen 2006). These new ways of being, need to be consistent with the change in the nature of our workplaces. That is, leadership should be such that it assists to end attachments to old structures or roles and create new contexts for work (Porter-O'Grady \& Malloch 2003).

Wheatley (1999) laid the groundwork for deeper investigation into the utility of the new sciences as a way of conceptualising and understanding leadership in the 21st century. She focused on, (1) order out of chaos, (2) information forming and informing us, (3) relationships that enrich and allow for diversity and (4) a vision as an invisible field that can enable us to recreate our workplaces and our world. Although Wheatley's ideas have been viewed by some as more metaphor than science (Stacey et al. 2000:143), she made ideas that had previously been the domain of physicists accessible and compelling to a much wider audience. Wheatley reflected on Weick's (1979:122) observation on the dilemma organisations face: 'The environment that the organisation worries about is put there by the organisation'. Axelrod and Cohen (2000:59) also provided a comprehensive description of complexity as applied to organisations, as these authors saw the complexity science approach as having rich possibilities for bridging the gap between 'hard science' and 'humanism'. Works such as Axelrod and Cohen, and Wheatley represent a definite move away from the mechanistic 20th-century paradigm of leadership. However, as we start to move away from old ways of thinking, there seem to be some ideas that are more difficult to let go of than others.

\section{The living present and a changing conception of time}

From a transformative point of view, the future is under perpetual construction, rather than predetermined as in rational causality. This means that human interaction that takes place in the living present perpetually modifies and 
shapes the future. The concept of time plays a central role in understanding organisations as complex responses processes (CRPs) and warrants further discussion. We agree with Fonseca's (2002) definition of an organisation as a temporary stabilisation of themes or habits that serve to organise the experience of being together that takes place locally and in the living present.

CRPs represent another decisive step away from the mechanistic leadership models of the previous century. Stacey et al. (2000) felt this terminology (i.e. CRPs) was needed to differentiate their view of complex relational human organisations from the more commonly used terminology of complex adaptive systems that leads us to think of human organisations as objectified systems. The theory of CRPs is, in essence, a theory of the process of human interaction (Stacey et al. 2000). A key concept that is essential in understanding organisations as CRPs, is the idea that human communication and the act of relating occurs in the living present (here and now). The living present provides a starting point for conceptualising causality in a new way. Rather than thinking of causality in a traditional rational way (moving toward a mature state or pre-selected goal), focusing on the living present allows us to conceptualise causality in a transformative way.

Choice and intentionality arise in, and influence, the microtime structure of the living present. This brings us to the nature of novelty or change. In transformative causality, the future is under perpetual construction and is changed by our movement toward the future: 'The future is unknowable but yet recognizable' (Stacey et al. 2000:52). From a CRP stance, human interaction is understood as paradoxical and dialectical (Fonseca 2002; Stacey et al. 2000) and our movement toward the future is movement toward an unfinished whole rather than a finished state.

\section{Non-causality and systems thinking}

One concept we seem reluctant to let go of is the rational view of causality. Rationalism frames the organisation as progressing toward predetermined or preselected goals (the rise and popularity of strategic planning in the 20th century is a manifestation of rationalist causality). The rationalist view of causality is that organisations are moving toward a future that is preselected by the organisation or toward some other finished state (Stacey et al. 2000).

Another lingering organisational lens that is used extensively is systems thinking. Early on, systems were viewed as machines and, later, we came to use systems thinking as a way to see organisations as living systems. Either way, systems thinking has been criticised for having an objectifying bias (Hamalainen \& Saarinen 2006:17); that is, the person looking at the system necessarily views himself or herself as external to that system. The 'detached observer' is an easy and comfortable position for most people, as it has been used in many of the organisational leadership tools developed in the 20th century. However, organisational life in the 21st century is highly complex and relational and third-person, detached views of organisational life fail to address the crux of leadership today. A new way of seeing and conceptualising organisations is needed.

\section{Informationology}

Modern management has changed with the advent of an information-based economy. Information has changed interactions - with each other, with business and between businesses and entities. With information, there are a plethora of new meanings and decisions, there is a change in relationships and there is a change in the very way we conduct ourselves as individuals, as leaders and managers and as organisational entities (Pellissier 2001). Some of these are, (1) relationships and communication, (2) the elasticity of knowledge, (3) an over-reliance on experts, (4) the trade-off between richness and reach, (5) a tendency to control and (6) speed and innovation.

There are many roles of information, some of which may even overlap (Anderson 1995; Shenk 2009), including:

1. as a complexity (the more information required specifying a system, the more complex it is)

2. as memory (information is a record of accumulated knowledge)

3. as communication (information is a means of social interaction)

4. as intellectual property (information with legally defined ownership interests)

5. as market enabler (information that permits efficient markets to function)

6. as context (information regarding the location, time or environment where the action takes place (Google, in itself, presents a self-organising system organising around and following questions asked)

7. as enabler for social interaction (hits are highly visible in the rapidly growing social networks such as Facebook, Google+ and Twitter, by establishing links and building relationships as a 're-tribalisation' of humanity, as expressed by Shenk [2009:932] when he talks about strict censorship of Internet connections in repressive governments).

\section{Growing complexities of resource allocation and the need for different planning models}

The process of planning has to articulate the strategy and the management of that strategy. From planning comes the vital means of connecting the mission of the present to the vision of the future. Part of addressing goals, objectives and strategy implementation, involves the allocation of resources within budgetary constraints. This handicaps flexibility by its focus on cost cutting and efficiencies. Mostly, the budget defines the plan that defines the strategy.

Peterson (1999) addressed an essential ingredient of strategic planning - the organisational and environmental interface. Institutional planning must include a comprehensive process of monitoring and adjusting for realities of the external 
environment (Taylor, De Lourdes Machado \& Peterson 2008). Complexity encourages a segmentation of the environment. This allows for the impact of the environmental factors on resources and resource flows to be examined, which helps determine resource predictability and the environmental locus of control with regards to resource flows. The strategic management and competitive advantage processes become linear and sequential rather than being seen as one set of activities, related and linked as one. This kind of planning relates more to operations than to strategy. Furthermore, resource allocation is not a linear process and cannot directly lead to strategy selection and implementation as is required in a linear model. This planning style does not relate to the need for adaptability with regards to the environment. The main goal of the strategic planning and implementation should focus on growth and maturity and not on internal processes and resources.

\section{Innovation}

Generally speaking, innovation is knowledge used in a unique and different way. Innovation is new thinking. That thinking can be radical, disruptive or incrementally different. But it is not more of the same - it is renewal and renovation. Innovation is generally the result of cumulative dynamic interaction and learning processes involving many stakeholders. Here innovation is seen as a social, spatially embedded, interactive learning process that cannot be understood independently of its institutional and cultural context (Cooke, Heidenreich \& Braczyk 2004; Fornaciari \& Dean 1998; Lundvall 1992). Because Roberts's (1999) definition (of innovation) maintains that an innovation can only be seen as innovation if it is has implementation and commercial value, it is important to measure the impact of innovation. Ravichandran (2000:263) believe that measuring the impact of innovation activities will depend on:

1. the typology

2. the degree of departure from the preceding product or service or process

3. the extent of usefulness of the innovation

4. the volume of profitability generated.

Smith (2010) identifies four types of innovation based on the work conducted by Henderson and Clark (1990):

- incremental (refining and improving the existing design within an established architecture)

- modular (use is made of new technology and components, within an existing system)

- architectural (an established system links existing components in a new way)

- radical (involving a completely new design using new components).

In the last case, the innovation can be disruptive. Henderson and Clark's (1990) framework shows that systems and components in innovation are inextricably linked, for instance, architectural innovation reconfigures an established system to link existing components in a new way. We like to define innovation as a continuum of activities incorporating the above notions: innovation as renovation is the outcome of a series of interrelated activities on a continuum, starting with creative discovery, then entrepreneurship and, finally, commercial exploitation. In this, leadership is redefined, processes, systems and culture may be redesigned and organisations search for and find new meaning. This definition allows for technological (product or process) innovation but also includes organisational or management innovation activities.

Innovation within the framework of a knowledge-based economy goes far beyond the linear or chain linkage models that have long been used in innovation theory to explain innovation processes in high-tech knowledge industries. Strambach (2002) suggests that the interdisciplinary view of innovation systems is concerned with understanding the general context of the generation, diffusion, adaptation and evaluation of new knowledge, which determines innovativeness. It follows that the focus is on non-technical forms of innovation as defined above. Common characteristics of the different approaches to innovation, as identified by Edquist (1997), include, (1) innovation and learning at the centre, (2) a holistic and evolutionary perspective and (3) an emphasis on the role of institutions. The increasing interdependence of technological and organisational change is a significant feature of systems of innovation, which means that technological innovation and organisational innovation have become increasingly important. These are combined with more diverse knowledge requirements, which include not only technical know-how, but also economic, organisational and sociological knowledge and competencies. The second reason for the increased interest in non-technical innovations is associated with the connection between the organisational innovation and the corresponding learning capacity. The acceleration of change that is part of the globalisation process means that organisational learning processes are becoming increasingly important for creating and maintaining competitiveness.

Some innovation theorists (such as Smith 2010) believe innovation is meaningless without technology. Technology is a great platform for innovation achievement, but it is certainly not the only one. Technology is a good enabler for certain types of innovation. But real innovation comes from the inner self and individual contributions and thoughts need to be given a place in organisations and in society to breed. We know that innovation takes place in the domains of product, process and/or service. However, there is more: innovation also takes place in leadership, culture, processes and systems, design, products and technology. Innovation is a thinking skill more than a doing skill. It transforms our views of current reality and focuses on renewal and regeneration. Zohar (1990) believes that:

Most transformation programs satisfy themselves with shifting the same old furniture about in the same old room. Some seek to throw some of the furniture away. But real transformation requires that we design the room itself. Perhaps even blow up the old room. It requires that we change the thinking behind our thinking - literally that we learn to rewire our corporate brains. (p. 114)

However, Zohar's 'real transformation' is really innovation. 


\section{Technological innovation is not enough}

Technological innovation comprises implementing technologically new products and processes and significant technological improvements in products and processes. The product or process should be new from the point of view of the firm that introduces it. In statistical and innovation research based on the Oslo Methodology (Organisation for Economic Co-operation and Development 2005), innovation covers all possible grades of novelty: from products and processes new globally (known as absolute innovations), through products and processes new on a market or in a country, where a given firm is operating, to products and processes new only to a given firm, but implemented in other firms, domains of activity or countries (so-called imitation innovations). Technological innovation is, in itself, undergoing change with the shifts in industrial revolution. This is the result of the evolution of technology. We summarise this as occurring in three industrial revolutions Firstly, there was the birth of the factory (e.g. tasks completed by hand in weavers' cottages are now completed in single cotton mill, leading to the mechanisation of textile industry), which developed around the late-18th century in Britain. Secondly, were the moving assembly line and mass production fostered by Henry Ford in the early 20th century. Both these revolutions led to enormous wealth and urbanisation. The third industrial revolution, on the other hand, is the result of digital manufacturing and technology convergence - clever software, new materials, dexterous robots, new printing (e.g. three-dimensional printing) and Web-based services. This has resulted in mass customisation and, as a revolution, has several consequences:

1. customers are happy because of faster lead times and better products

2. governments providing subsidies favour the previous products and services in order to protect their investments

3. the lines between manufacturing and services are becoming blurred.

Technological innovation is created as a result of innovation activity comprising scientific research, technical, organisational, financial and market activities in order to improve a product, process or system. Technical or esthetical modifications that do not influence the performance, property, costs, et cetera, are not considered technological innovations. Generally, we are concerned with process innovations - 'performing an activity in a radically different way' (Davenport 1993:10), service innovations 'a new way of providing a service, often with a novel and very different business model ... even an entirely new service' (Smith 2010:23) and product innovations - 'a core design concept that performs a well-defined function' (Abernathy \& Clark 1985). Product, process or service innovations thus comprise both systems and components, calling for an integrative model for innovation beyond the instrumentalism versus radicalism approach of the past.
Organisational innovation encompasses all of these, whilst highlighting the way businesses operate (Birkinshaw, Hamel $\&$ Mol 2004). These authors maintain that organisational and management innovation is difficult, as it questions existing practices and processes and our assumptions on the nature of the way things are and therefore places an enormous responsibility on leadership acknowledging complexity in order to innovate. In this article, we will focus more on the latter.

Whilst innovation concerns the processes of implementation, relying mainly on organisational communication and power in the domains of production, adoption, implementation, diffusion, or commercialisation of creations (Spence 1994), creativity remains exclusive to the relation established between the creator and his product, where not even originality and usefulness are important, but only the notion of 'trying to do better'. The latter is connected to cognitive and emotional processes taking place at the individual level (Sousa, Monteiro \& Pellissier 2008; Sousa, Pellissier \& Monteiro 2009a, 2009b). If we relate creativity to problem definition, and innovation to decision implementation, this last step requires a series of problem definitions, in order to carry out a decision or an idea, thereby making it difficult to separate these concepts at an organisational level. In fact, when we move from the individual level to the team and organisational levels, creativity and innovation become increasingly difficult to separate, so that we must agree with Basadur (1997), when he says there is no difference between organisational creativity and innovation. Therefore, the moment we move to other levels besides the individual, we will use these terms (creativity and innovation) as synonyms, referring to organisational creativity as a system devoted to enhance creativity in organisations and thus using the definition proposed by Basadur (1997).

As to the several approaches to identify types of innovation, either by separating the adoption of products and processes from its development (Cebon, Newton \& Noble 1999) or, in a more classical way, product and process innovation (Adams 2006), most authors agree that innovativeness, or organisational (and management) innovation, is a separate type of innovation, which represents the potential of the workforce to promote changes to benefit of the organisation. As Huhtala and Parzefall (2007:299) mention, 'to remain competitive in the global market, organisations must continuously develop innovative and high quality products and services, and renew their way of operating', and they also maintain that companies increasingly rely on the employees' continuous ability to innovate. Also, even though innovation may take place through the adoption or development of an existing product or service, through investments in research and development (R\&D) or in technology acquisition, it is only through developing and sustaining a creative workforce that the organisation will succeed in maintaining the necessary potential to overcome difficult problems and situations that cannot be solved through investments only (Cebon et al. 1999). To this end, technological innovation is seen as a result of an innovation activity comprising research (scientific), technical, 
organisational, financial and market activities. Technological innovation means objective improvement of the properties of a product or a process or a system of delivery relatively to the already existing products and processes. Less significant, technical or aesthetical modification of products and processes which do not influence the performance, property, costs or materials consumption, energy consumption and components consumption are not considered technological innovations. As Desrochers (2001) puts it, technological innovation can manifest in any business activity, for example in a basic activity, as well as in secondary and other activity (as defined in the system of national accounts), and in the auxiliary activity of sales department, accounting department, IT department et cetera (e.g. the computerisation of a sales department or a finance department of the enterprise can be considered a technological innovation).

The creative workforce potential is both the ability to retain creative managers and employees (Macadam 2006) and to provide an environment where each one will feels free and willing to contribute to organisational success. Aspects such as raising job complexity, employee empowerment and time demands, together with low organisational controls (decision-making, information flow and reward systems), are said to raise employee creativity (Adams 2006). However, more elements are necessary in order to make people willing and able to contribute to organisational effectiveness. For instance, supportive leadership, knowledge acquisition and team work procedures favouring creativity (Unsworth 2005) can add to success. Creative people (either managers or employees) are committed to their work and organisation and so they may bring in important issues, provided that top management values their work and ideas. In fact, according to a Gallup Management Journal survey (Hartel, Schmidt \& Keyes 2003), engaged employees are more likely to 'think outside of the box' and produce creative ideas than disengaged people; they also are more receptive to new ideas. The research concludes that engaged people tend to find and suggest new ways to improve their work and business processes, which may lead to the assumption that creative people have a deeper understanding of the organisational processes, by being in a privileged position to identify, define and find organisational problems.

To a certain extent, most of these can be achieved by the implementation of complex systems and the concept of resilience engineering to the business fundamentals. This is attained by elevating the importance of creativity and entrepreneurship and providing a system through which current goals are realised by new ideas and can flourish. What is required is the freedom to create, the content and process skills to be able to create and a supportive human environment (peers and team leader). The issues surrounding the potential of an organisation to innovate are still in its beginnings, although McLean (2005), Puccio et al. (2006) and, especially, Basadur (1987, 1994, 1997), have all engaged in empirical research in this regard. The major challenges are to define criteria to evaluate the impact of organisational innovation on process and product innovation (Wolfe 1994).

In organisational innovation, the unit for innovation is the organisation itself (Wolfe 1994). Although the outcome of the innovation may be process, product or service, the innovation needs to be undertaken through the creative inputs of the individuals and/or management. As to measures of innovation, Dalal (2008) mentions the qualitative measure of emotional and psychological impact the innovation produces on the users (the 'aha!' moments), the quantitative measures of the total population of end users using the new innovation (and even helping co-create it) and the net new revenue generated for the company that can be attributed to the new innovation.

\section{Complexity-based emergent management theory}

Complexity allows a two-tiered focus in business, (1) its performance system, which is responsible for the performance of current goals and tasks for immediate survival and (2) its adaptation system, which is responsible for the longterm sustainability through the generation of new ideas, operations and behaviours. It generates possible futures for the total systems. Successful resilient organisations should be robust in terms of both subsystems but tend to concentrate on only one (Robb 2000). The term 'complexity' has two distinct applications (Standish 2008), namely, (1) as a quality (i.e. complexity deals with our ability to understand a system or object) and (2) as a quantity (i.e. complexity deals with something being more than complicated). Complexity as a quality is what makes the systems complex and complexity as a quantity describes, for example, human beings being more complex than a nematode worm. Thus, complex systems constitute a class of systems that are more difficult to deal with than traditional analytical systems. For this reason, complex and simple systems form a continuum, characterised by the chosen complexity measure. The two applications of complexity are inherently observer or context dependent, leading to a disparate collection of formalisations of the term. Thus, being able to establish easy to measure proxies for complexity is often important and most proposals for complexity are of this nature (Standish 2008:10). Complexity as a quantity can normally be decomposed in a linear way and can be directly compared (e.g. $5 \mathrm{~cm}$ can be broken into five equal parts and directly compared). Complex systems, on the other hand, cannot be divided and the individual segments compared. This is because of the interrelations between the subsystems that can quickly lead to combinatorial explosions. This leads to three definitions of complexity (Standish 2008). Firstly, there is the number of parts definition (e.g. a car is more complex than a bicycle because it has more parts, but a pile of sand is not as complex because each grain of sand is conceptually the same and the order of the grains is not important). Secondly, there is the definition relating to the number of distinct parts (e.g. both a shopping list and a Shakespearean play consists of the same 26 letters of the alphabet, this is not a good measure of complexity). Lastly, there is a context-dependent definition of complexity. 
When we relate business to complex adaptive systems (CAS) - also called learning systems (Robb 2000) - we look for ways to successfully adapt to changing environmental conditions. Complexity science focuses on relationships between individuals, teams or between organisations and businesses. Accepting business as being a complex system requires that we acknowledge that we cannot control organisations to the degree that a mechanistic perspective will imply, but only that we can influence where the organisation is going and how it will evolve. From this view, organisations are CAS nested in larger CAS (for instance, the economy or the country in which it is based, or the industry in which it operates). Lastly, complexity science allows an organic view of organisations and its resources. Resilient organisational structures, in focusing on the skills, culture and architecture, address this matter and will be discussed in a separate section.

Simon (1996) defines a complex system as one made up of a large number of parts that have many interactions. Complex systems change inputs to outputs in a non-linear way because the components interact with each other through a web of feedback loops (Anderson 1999a:217). Thompson and MacMillan (2010:6) describe a complex organisation as a set of interdependent parts which, together, make up a whole that is interdependent with some larger environment. In organisation theory, complexity is treated as a structural variable that characterises both organisations and their environments. In terms of the first mentioned, Daft (1992:15) equates complexity with the number of activities or subsystems within the organisation. This, he maintains, can be measured along three dimensions, namely, (1) vertical complexity (the number of levels in the organisational hierarchy), (2) horizontal complexity (the number of job titles or departments across the organisation and (3) spatial complexity (the number of geographical locations. With regards to the environment, complexity is equated with the number of different items or elements that must be dealt with simultaneously (Scott et al. 1998:230). Galbraith (1982) proposes that organisational design should try to match the complexity in structure to complexity in environment. Casti (1994) points out that, in non-linear systems, interventions to make a change to one or two parameters can drastically change the behaviour of the whole system. Moreover, the whole can be very different from the sum of the parts.

CAS consists of agents that interact with each other and, in doing so, generate new behaviours for the systems as a whole (Lewin \& Regine 1999). These lead to the following caveats:

- Patterns of behaviour in these systems are not constant.

- As the system's environment changes, so does the behaviour of its agents. Thus, the behaviour of the system as a whole can change.

- Complexity science focuses on relationships between individuals, teams or between organisations and businesses.

- Business as a complex system requires acknowledgement that we cannot control organisations to the degree that a mechanistic perspective will.
- CAS allow for an organic perspective and the ability to deal with the human element in process design.

Complex designs are formulated to attend to the tensions of paradoxical strategies which may emanate from inconsistencies or contradictions in the products, services, marketplace, processes, rewards and/or competencies associated with different strategies (Smith 2010). Considerable attention has been given to agent-based models of organic systems (McKelvey 1999). In modelling complex systems, we should note that agent-based models need to avoid adoption of social concepts that assume away many of the phenomena of interest. In fact, McKelvey (1999) argues, if at least some social phenomena, which are typically assumed to arise through rational behaviour, arise instead because of complex dynamics that are little influenced by conscious intent, then we need to allow for this in the foundation assumptions incorporated into the model design. In artificial intelligence, for instance, attempts to accommodate rational order have involved incorporating simplified rule sets or incorporation into agent design.

\section{Linking complexity and innovation}

What do these two phenomena have to do with each other? Complexity science is the scientific study of complex systems. These systems have many parts that interact to produce patterns of behaviour that cannot readily be explained by the behaviour of its individual elements. Therefore complexity in business helps us better understand the importance of relationships and the interactions of innovations. Complexity science is used in modern business applications because of its ability to explain change and stability and the underlying dynamics produced by patterns in systems and, most importantly, self-organisation and emergence. This means that individual agents in a system cannot control the behaviour or the outcomes of the system because these agents are the consequences of interactions within the system and with other systems. Consequently, complex systems are, by nature, unpredictable and can lead to renewal and change (radical or otherwise). This makes complexity science invaluable to innovation. From an innovation point of view, this means that the best way to understand the dynamics of change and innovation is to employ complexity science.

Yet, complexity science does more than that - it allows for diversity, relationships and cooperation. Complexity science changes how management works. The inherent self-organisation and unpredictability mean that there is less control. Leadership thus requires change as there is less control and more focus on small actions to influence patterns of interaction. Smaller organisations are, of course, more flexible and thus more able to be innovative. Thus, the size of the organisation counts because it is easier to develop relationships and creativity in a smaller group and there may be a greater willingness to release control. Larger organisations seem to become inflexible and rulebound. Their flexibility is normally embedded in specific units, but overall, there is a notion that adaptive and resilient systems are characterised by order or disorder, or stability or flexibility. In a complex environment, there is no 'either/or'. 
To apply complexity to innovation, one needs certain principles. Zimmerman, Lindberg and Plsek (2012) suggest the following:

- The provision of opportunities for a diverse group of people to interact creatively.

- The design of processes to develop creativity, for example, appreciative enquiry, open space, conversation cafes.

- The adoption of a shorter-term perspective stimulating experimentation and sense-making of the ideas, instead of developing a grand plan or long-term blue print.

- The management of innovation should be centralised (to develop an innovation culture organisation-wide) and decentralised (encouraging experimentation at the local level). This is the principle of non-linearity, where the strategy allows small changes effecting large-scale change.

- Leadership should have the ability to listen to promising developments, create network opportunities and communications across the organisation and allow for pattern recognition and new innovations to unfold.

Complexity science requires a change in leadership to support the innovation. This new leadership should:

- Create a culture of innovation. Leadership cannot make innovation happen, but they foster innovation by providing the time and space for creativity, communication and interaction.

- Listen and learn to determine what is emerging in the organisation or in its environment.

- Learn by taking risks and allowing experimentation in the form of ideas or processes.

Two frameworks in this regard are proposed below. Framework 1 employs complexity and CAS in innovation, whilst framework 2 uses a reductionist approach seeing complexity as something negative to the organisation.

\section{Framework 1: Using complex adaptive systems}

Rosen (1991) founded the school of thought which believes that complex systems cannot be described by a single best model, as reductionists promote. Instead, a whole collection of models exist that, in the limit, collectively describe the system. Standish (2008:9) mentions that in all cases of recognised emergence, the observer has defined at least one semantic and one syntactic model of the system; these models are 'fundamentally incommensurate'. Moreover, emergence in this sense can be called complex. Models that have a finite specification can never be complex, because the specification contains all there is to know about the system - the more complex the system, the less knowable the organisation is (Perrow 1967); however, it is not so easy with non-linear systems. Obviously, causal models are inadequate because of their interconnectedness and feedback loops, even when the relationships between the independent and dependent variables are denoted by some logarithmic or exponential function. There are six important aspects to be considered in modelling complex systems (Anderson 1999b; Kaufman 1993):
- Many dynamic systems do not reach either a fixed-point or a cyclical equilibrium.

- Processes that appear to be random may be chaotic, revolving around identifiable attractors deterministically and rarely return to the same state.

- The behaviour of complex processes can be quite sensitive to small differences in initial conditions, so that two entities with similar initial states can follow radically different paths over time.

- Complex systems resist simple reductionist analyses because their interconnectedness and feedback loops preclude holding some system constant in order to study others in isolation. Because descriptions at multiple scales are necessary to identify how emergent properties are produced, reductionism and holism are complementary strategies in analysing such systems.

- Complex patterns can arise from the interaction of agents that follow relatively simple rules; that is, emergent patterns can appear at every level in a hierarchy.

- Complex systems tend to exhibit self-organising behaviour; that is, from starting in a random state, they usually evolve toward order instead of disorder.

There are many forms of dynamic systems, for example, general systems theory, cybernetics, chaos theory or catastrophe theory - all of which address systems where a set of equations determine how a system moves through its state space over time. Another modelling technique examines regularity that emerges from the interaction of individuals connected in CAS. The presiding feature is that at any level of analysis, order is an emergent property of individual interactions at a lower level of aggregation. Anderson (1999b), in his study of complex organisations, found that these organisations exhibit non-linear behaviours. He found that these organisations characterise four key elements that are prevalent in organisation design, namely:

1. agents with schemata

2. self-organising networks sustained by importing energy

3. co-evolution to the edge of chaos

4. system evolution based on recombination.

It follows that organisational designs for complexity will require incorporation of these elements. Specifically, complex organisations establish and modify environments within which effective, improvised self-organised solutions can evolve and managers influence strategic behaviour by altering the fitness and landscape for local agents and reconfiguring the organisational architecture within which the agents adapt. Lewin and Regine (1999) identify five principles in CAS:

- Agents interact and mutually affect each other in a system - this focuses on relationships between and amongst people, teams and companies.

- Agents' behaviours in a system are governed by a few simple rules - in business, rules become practices and these practices are guided by shared values and beliefs.

- Small changes can lead to large effects, taking the system to a new attractor - multiple experimentation on a small scale is the most productive way to lead change rather 
than to attempt to leap too quickly to a perceived desired goal on a large scale.

- Emergence is certain, but there is no certainty as to what it will be - create conditions for constructive emergence rather than trying to plan a strategic goal in detail. This includes nurturing the formation of teams and creativity within teams and evolving solutions to problems (not designing them). Hierarchical and central control should give way to distributed influence and a flat organisational structure.

- The greater the diversity of agents in a system, the richer the emergent patterns - seek diversity of people in terms of culture, expertise, age, personalities and gender, so that people interact in teams (thus creativity has the potential to be enhanced).

A substantive element of complexity in organisational designs is made up of organisational resilience. Robb (2000) defines a resilient organisation as one able to sustain competitive advantage through its capability to deliver excellent performance against current goals, whilst effectively innovating and adapting to rapid, turbulent changes in the environment. The first requires consistency, efficiency, elimination of waste and maximising short-term results, whilst the second requires foresight, innovation, experimentation and improvisation, with an eye on longterm benefits (Johnson-Lenz 2009). The two modes require different skills sets and organisational designs (e.g. the move from 'just-in-time' production to 'just-in-case' resilience). These organisations exhibit particular characteristics in the sense that they, (1) can create structure and dissolve it, (2) provide safety in the face of change (although this is not necessarily security or stability), (3) manage the emotional consequences of continuous transformation, change, anxiety and grief and (4) learn, develop and grow. The resilience community agrees that resilience architecting (also called resilience engineering) occurs over the three phases of a disruption. In the pre-disruption phase, the system should take steps to anticipate the disruption and avoid the disruption, if possible. In the survival phase, the system should absorb the disruption so that it can recover in the recovery phase. In the recovery phase, the system resumes some degree of its original goals, including the survival of the humans in it. Disruptions are the initiating event that may lead to a catastrophic event. Disruptions may be either external, such as terrorist attacks or natural disasters, or internal, such as human or software errors.

Resilience has four primary attributes: capacity, flexibility, tolerance, and inter-element collaboration. Capacity requires that the system be sized to handle the maximum and most likely events, such as terrorist attacks and natural disasters. However, a system cannot depend on capacity alone; the other attributes must be present to handle unpredicted events. Capacity includes functional redundancy. Flexibility requires the system to be able to reorganise. For example, plans must be in place to allow the command and control to shift upwards in the event of a serious disruption, such as a terrorist attack. Tolerance allows the system to degrade gracefully in the face of an attack; that is, all resources would not become inoperative after the first strike.

One of the most important resilience attributes is inter-element collaboration. This attribute allows all elements of the system to interact and cooperate with each other as in collaborative innovation systems. There are numerous activities relating to resilient organisations, these are (Pellissier 2011:156):

- Resilient organisations actively attend to their environments: Monitoring internal and external indicators of change is a means of identifying disruptions in advance. Resilient organisations seek out potentially disturbing information and test it against current assumptions and mental models. They work to detect the unexpected so they can respond quickly enough to exploit opportunity or prevent irreversible damage. In short, they anticipate being prepared.

- Resilient organisations prepare themselves and their employees for disruptions: Attentive preparations build a team that imagines possibilities and displays inventiveness in solving problems. Managers know how and when to allow employees to manage them for focused productivity as well as adaptive innovation. Resilient organisations cross-train employees in multiple skills and functions. They know that when people are under pressure, they tend to revert to their most habitual ways of responding.

- Resilient organisations build in flexibility: Even whilst executing for lean and mean performance, resilient organisations build in cushions against disruptions. The most obvious approach is the development of redundant systems - backup capacity, larger inventories, higher staffing levels, financial reserves, and the like. But those are costly and not always efficient. Flexibility is a better approach.

- Resilient organisations engage suppliers and their networks in devising makeshift solutions to temporary disruptions, thereby using flexible strategies: They implement policies that encourage flexibility in when and where work is undertaken. Employees who are used to telework and virtual workspaces adapt more quickly and are more productive following a crisis. In addition, research shows that flexible work practices contribute to greater employee resilience, productivity, commitment and to lower levels of stress.

- Resilient organisations strengthen and extend their communications networks - internally and externally: A robust and redundant communications infrastructure holds up in a crisis. Social networks amongst employees at resilient organisations are rich, varied and visible. People who have trust relationships and personal support systems at work and with friends and family are much more able to cope with stress and change. Good connections and communications also apply to external relationships with suppliers and customers. A key is to recognise what is important to meet organisational goals and to listen to those with needed expertise and ideas wherever they are in the value web. Resilient organisations use networked communications to distribute decision-making. As much 
as possible, they push decisions down to where they can be made most effectively and thus quickly. This, in turn, requires good access to information at all levels of the organisation.

- Resilient organisations encourage innovation and experimentation: In times of great uncertainty and unpredictability, the success and failure of small-scale experiments can help map a path to the future. Resilient organisations engage in market research, product development, and ongoing operations and service improvements. They invest in small experiments and product trials that carry low costs of failure.

- Resilient organisations foster a culture of continuous innovation and ingenuity to solve problems and adapt to challenges: A side benefit is that employees who believe they can influence events that affect their work and lives are more likely to be engaged, committed, and act in positive ways associated with resilience. Some organisations also have internal idea markets to surface new ideas and innovations. Others use 'crowdsourcing' to engage people externally in solving a given problem.

- Resilient organisations cultivate a culture with clearly shared purpose and values: When an organisation's sense of purpose is shared by its employees, suppliers and customers, those networks can provide flexibility to help it through a disruption. Engaged employees will seek out opportunities to try new approaches, find creative solutions and achieve great results.

\section{Framework 2: Complexity reduction}

The second framework tries to reduce complexity and sees complexity as negative towards the organisation. It is not easy to compress non-linear systems into a parsimonious description. Simon (1996:1) believes that the central task of the natural sciences is to show that complexity is but a mask for simplicity. In the Social and Management Sciences, the tendency seems to be to reduce complex systems to simpler ones by abstracting out what is unnecessary or not important. Most organisational scientists, who view organisations as natural systems, point out that rules often do not govern actions and that rules can change without behavioural consequences and behaviour can change without modifications to rule systems (Scott 1992).

Normally, competitive advantage is about new product development and the introduction of distinctive offerings. In fact, technological innovation seems to be the most prevalent form of innovation. There is a school of scientists that believe that the longer an organisation has been in existence, the less likely it will allow for radical innovation (Anderson 1999a).

The literature abounds with case studies about innovators and entrepreneurs who make things happen. However, there is a point where the innovation leads to a decrease in profitability because of the complexity that it incurs. The continued launch of new products and services or changes in design or movement styles lead to complexity. This is supported by a survey conducted by Bain Consulting (2012), which found that excessive complexity increases costs and slows growth because of the way complexity gets embedded in the supply chain. The corporate response seems to be to launch an intervention (such as lean manufacturing or six sigma). This, however, does not simplify complexity; it merely reduces it in certain areas. There are numerous reasons for the spread of complexity: bad economic data, overly optimistic sales expectations, entrenched managerial assumptions and, in developing economies: globalisation, labour problems, customisation versus market size one, new technologies, political instability, lack of infrastructure, resources and capacity, and lack of planning. Bain Consulting (2012) believes that downturns reveal organisational weaknesses and that a nimble, focused organisation could become 'sluggish and ineffectual' in a period of downturn. They see a major cause of this sluggishness as complexityproduct complexity, organisational complexity and process complexity. The costs of complexity are usually hidden, so CEOs are often unaware of the magnitude of the problem. When the downturn hits, CEOs may feel unsure how to tackle it or fail to identify the short-term actions that can reduce costs and create flexibility so the company can adjust to the new market conditions. They may also neglect the longer-term steps necessary to balance complexity reduction with innovation as the company pulls out of the downturn and begins to grow consequently - there needs to be a balance between innovation and complexity. Consider manufacturing, which is a strong American economic enabler. From a strategic point of view, the addition of new products increases growth. From an operational point of view, this addition adds complexity and thus decreases profitability. Moreover, increased customisation results in unexpected demand peaks that can easily lead to a drop in quality. The traditional financial systems are unable to account for the relationship between product proliferation and complexity costs, as the costs are embedded in the way the organisation undertakes its business. There seems to be an optimum point for innovation, unless there is a management of the resultant complexity (Gottfredson \& Aspinall 2006).

Some protagonists believe in reduction to diffuse complexity. For instance, Gottfredson and Aspinall (2006) proposed a 'Finding the model T Ford' approach. The approach is based on determining the innovation 'fulcrum'; that is, determining the right balance between innovation and complexity. The following practices are required:

1. Raise the bar: requiring a higher rate of return on new products not only makes it more difficult to arbitrarily add variations, it also boosts internal innovation discipline.

2. Postpone complexity: the farther down the value chain complexity is introduced, the less it costs.

3. Institutionalise simplicity in decision-making: executives must pinpoint responsibility for innovation decisions.

4. Stay balanced: a company's innovation fulcrum can shift. Sometimes customers value cost and quality more than having choices.

Technology, postponing complexity to later in the value chain and changing customer tastes can all affect where the right fulcrum point is located. 


\section{A comparison between developed and developing organisations}

In a study of 14 mid-sized organisations from either a developed or a developing economy, the respective CEOs were interviewed. The purpose of the study was not to generalise but functioned as a pilot study to determine issues of complexity and organisational innovation between the two economic entities. Seven middle-sized South African companies were selected as the developing economy partner and seven middle-sized US companies were selected as the developed economy partner. The CEOs of each were asked to describe their understanding and deployment of organisational innovation and complexity. They were also given a set of complexity and organisational design issues and asked to comment about the extent to which their companies were exposed to these and how they perceived the solutions. The interviews focused on the extent of their organisational innovation and their understanding and implementation of complexity to achieve the innovation. Below is a sample of responses from four of the companies involved in the study.

\section{Company A}

This is a medium-sized US firm specialising in health and education research and operating out of several cities in the USA. According to the CEO, larger, more nimble firms had better systems to enable them success, whilst, in Company A, there was an over-focusing on quality and accreditation of research outputs rather than on market position and competition. Two primary problems existed: an over-emphasis on research quality and an under-emphasis on efficiencies, both of which lead to budget constraints. Operational problems included inefficiencies and lack of structure. This company's strategy seems to rely on a reengineering approach in terms of the following elements:

1. appointment of senior research specialists

2. building teams

3. creation of management systems and accountability

4. change in culture

5. becoming client-focused

6. specialising on something specific.

Their strategy is certainly linear - in the CEO's own words, it is aimed at 'putting the firm on a straight path and staying on that path'. He also maintains that:

'A linear strategy was required because of the competitive nature and scale of the environment and a required change in one direction. We are not in a tumultuous environment and had to adapt to the new path and merely be able to stay on that path.' (CEO, Company A)

\section{Evaluation of Company A's strategy}

The CEO did acknowledge that there were two conflicting objectives - making money and being efficient - which may have required a complex solution, but, he felt that, as long as they stayed in the new path, they should be successful. The CEO did not understand the role or value of adaption, resilience or agility.

\section{Company B}

This is a medium-sized bank in the USA. When the current president of the bank took over, there was little wrong with the strategic direction; however, there was no vision, only the mission. The new president decided not to select objectives but identified three key priorities that inform their strategy and remain constant, (1) fiscal soundness, (2) focus on customers and (3) focus on the community. Believing that management has changed substantially over the last 20 years, the president practices the following with regards to strategy, which includes the following principles:

1. strategy is about common sense

2. strategy is a journey not a destination, with the journey indicating the general direction

3. it is important to track who you are

4. you need to communicate that you are a real person.

Further to this last point, the bank president states, 'Don't sit up there, go down to the people and ask them what they would do if they were president.' The elements of Company B's strategy were, (1) a flat organisational structure, (2) the use of teambuilding exercises and (3) a collaborative approach to management.

\section{Evaluation of Company B's strategy}

Employees felt confident enough to discuss issues inside the discussion room and not amongst themselves in the corridors, rather than resorting to complaints outside the discussion room. Company B featured a smaller management team and was subject to less interference from the Board. Although its structure was now flexible, some employees did not agree with the new approach and left the bank, thereby providing a natural exit for employees in disagreement with the general flow of the strategy and its implementation. Thus, there is stability within the unstable environment.

\section{Company C}

This is a medium-sized risk management venture in South Africa. The CEO, who, at the time of this survey, had been appointed for one year, sees his role as 'never lonely, participative and directive, experiential and experienced participative'. Their strategy consists of the following elements:

1. strategic management is very important, although flexible

2. strategy is monitored as a journey as often as twice a week

3. there are no 'analogue activities', only 'acting and thinking digitally'

4. engaging in strategic planning is a continuous process using the concept of a sense-making loop from uncertainty to a shared understanding

5. their intent is to manage future risks before they take place

6. the execution of their strategy employs action learning, experiential learning and serious play are the methodology framework for the planning sessions

7. a talent analysis, learning and communication styles linking assignments to a group of various competencies.

Teams change depending on the task. 


\section{Evaluation of Company C's strategy}

Strategy in Company C happens as continuous loops, rather than as a planned exercise. This strategy is very flexible and teams are formed based on a specific need. There is a feeling of openness and conviviality amongst the employees and the $\mathrm{CEO}$ is seen as friend and not as executive.

\section{Company D}

This is a medium-sized (family-owned) manufacturing organisation in South Africa, which also exports to other countries. In regards to how he views his role within the organisation, their CEO writes:

'At times I play the classic 'lonely' CEO, off by myself thinking and dreaming of what could/should be within the organisation. Creative inspiration or concrete decision may come at any time including during the wee hours, driving my daughters to school or while having lunch. I am participative during many "blue sky" meetings, where my role is decisive in theory but I am just another voice for the most part.' (CEO, Company D)

Strategy and innovation are seen to be linked and to provide the overarching framework for their daily actions, but putting too much emphasis on the process can choke the organics out of running an organisation. The CEO does believe in nonlinearity and will:

'Literally talk to everyone and anyone in the organisation on an hourly basis. I never assume that I have all the answers and many times the best ideas and concepts will arise from a chance encounter with a staff person. So I don't leave those encounters to "chance" - I create them often.' (CEO, Company D)

They are constantly re-evaluating their vision, mission, values and strategy using a process that includes regular meetings with top and middle management and by carefully listening to line-level employees and customers every day. Their main goals are to achieve a strong position in the industry-related marketplace, maintain a very high level of product quality and make their business a fun and interesting place to work and to turn a profit in doing so.

\section{Evaluation of Company D's strategy}

Company D's strategy is linear, with traces of non-linearity. Their strategies include marketplace analysis, competitive analysis and informal SWOT (strengths, weaknesses, opportunities and threats) analysis. Their strategy has changed from a 'shoot from the hip' organisation to one more analytical, reviewing numbers carefully.

\section{Discussion}

There can be no generalisation because of the small, nonprobabilistic sampling. However, some degree of relative comparison can be made and the pilot study sets the stage for a more robust study across the two economies to follow. From the interviews, a number of points came to light, including that more South African organisations were, by nature, complex, whilst more US organisations were, by design, linear, despite being inherently complex. The US companies were not comfortable with the CAS model and endeavoured to use some form of reductionism to achieve results when faced with complexity. Also, the US companies were more involved in experimental products, strategic alliances, meetings, communication with customers, communication within projects, but less so in teambuilding, exploitation (refining and extending existing technologies) and exploration (searching and experimenting with new technologies). In fact, it seems that South African companies are managed using complexity techniques and all innovation forms by nature, whilst the US ones favoured a reductionist approach focusing on technological innovation and trying to simplify structures and processes.

Technology was favoured by both groups as the factor most considered in a complex environment. As was expected, the US companies did not experience the developing economy indicators (problems with labour, productivity, clashing cultures, training and development, understanding and implementing new technologies, geographical dispersion, communication or quality). The South African companies had problems with: value and supply chains, new innovations, inadequate knowledge management and business intelligence, low capacity utilisation, no link between people and process, performance criteria and badly articulated connections between business units. On the other hand, the South African companies were more involved in exploiting and exploring opportunities and thus could be classified as engaging in the complexity suggested in Framework 1. Although this is not conclusive evidence, there seems to be adversity (even rigidity) in the US companies to explore forms of complexity and innovation other than, at most, technological innovation, and a feeling of comfort in reducing complexity, as per the proposed Framework 2.

\section{Conclusion}

Complexity is neither complicatedness nor overdetermination. Complexity is a cross-disciplinary field with its own approach to knowledge-creation that includes a set of methodological approaches. As such, it offers distinct and innovative perspectives on the evolution of systems and the behaviours of the actors within them. And, it should be noted that complexity, in itself, is not an 'either/or' to traditional management models. Instead, it expands and augments these models. Complexity theory is particularly relevant for organisations facing rates of external change that exceed their internal change (McKelvey 1999). Unlike systems with a fixed-point or cyclical equilibrium, the instability in the global environment has a more dynamic equilibrium in which actions can lead to small, medium or large cascades of adjustment.

Brown and Eisenhardt(1998) suggest that single business units achieve rapid evolutionary progress through improvisational moves based upon a few simple rules, responsibilities, goals and measures. These authors offer a new strategic paradigm for navigating the tumultuous markets:

the key strategic challenge facing managers in many contemporary businesses is managing this change. The challenge is to react quickly, anticipate when possible, and lead change 
where appropriate. A manager's dilemma is how to do this, not just once or every now and then, but consistently. (p. 23)

Synergy amongst units follows when units have distinct roles participating in the larger focus. Collaboration is focused on a few key areas. Evolution is preferred over the radical revolution preached and implemented by the re-engineers of the 1990s.

We agree that a nation's competitiveness lies in its innovativeness. Innovation is a dangerous beast that bodes evil and destruction when used inconsiderately because of the changes and possible aggravated complexity it incurs. This makes innovation management critical. It also requires a deep understanding of the nature and forms of innovation and a willingness to create opportunities for creativity. Technological innovation is not necessarily the best innovation. However, with an increasingly complex environment and complexity within the organisation following on innovations, organisational innovation seems required. In this research, a comparison was made between developed and developing economies with regards to how companies handle their innovations whilst coping with complexity. There is reason to believe that developing economies are more able to handle the extent of complexity than their developed counterparts.

This research is by no means final or complete. The pilot study should be extended to a bigger sample from both economies. Questions that need to be addressed include, (1) the extent to which complexity hinders or support innovation, (2) new typologies for innovation within a complex environment and (3) a point of convergence between developed and developing economies - when and why?

\section{Acknowledgements \\ Competing interests}

The author declares that she has no financial or personal relationships which may have inappropriately influenced her in writing this paper.

\section{References}

Abernathy, W.J., \& Clark, K.B., 1985, Resilience maps, viewed 02 February 2010, from http://www.provenmodels.com/571/transilience-maps/k.b.-clark--w.j.-abernathy

Adams, R., 2006, 'Innovation measurement: A review', International Journal of Management Reviews 8(1), 21-47. http://dx.doi.org/10.1111/j.14682370.2006.00119.x

Anderson, J.A., 1995, An introduction to neural networks, MIT Press, Cambridge.

Anderson, P., 1999a, 'Seven levers for guiding the evolving enterprise', in J. Clippinger (ed.), The biology of business: Decoding the natural laws of enterprise, p. 315 Jossey-Bass, San Francisco. http://dx.doi.org/10.1287/orsc.10.3.216

Anderson, P., 1999b, 'Complexity theory and organisation science', Organisation Science 10(3), 216-232.

Axelrod, R. \& Cohen, M.D., 2000, Harnessing complexity: Organisational implication of a scientific frontier, Basic Books, New York.

Bain Consulting, 2012, An exploration of the world economy, viewed 12 June 2012, from http://www.bain.com/publications/articles/

Basadur, M., 1987, 'Needed research in creativity for business and industrial applications', in S.G. Isaksen (ed.), Frontiers of creativity research: Beyond the basics, p. 298, Bearly Limited, Buffalo.

Basadur, M., 1994, Simplex: A flight to creativity, The Creative Education Foundation, Buffalo.

Basadur, M.S., 1997, 'Organisational development interventions for enhancing creativity in the workplace', The Journal of Creative Behavior 31(1), 59-73. http:// dx.doi.org/10.1002/j.2162-6057.1997.tb00781.x
Birkinshaw, J., Hamel, G. \& Mol, M.J., 2008, 'Management innovation', The Academy of Management Review 33(4), 825-845.

Brown, S.L. \& Eisenhardt, K.M., 1998, Competing on the edge: Strategy as structured chaos, Harvard Business School Press, Boston.

Casti, J., 1994, Complexification: Explaining a paradoxical world through the science of surprise, HarperCollins, New York.

Cebon, P., Newton, P. \& Noble, P., 1999, 'Innovation in organisations: Towards a framework for indicator development', Melbourne Business School Working framework for indicator development', Melbourne
Paper \#99-9, Melbourne Business School, Melbourne.

Center for Strategic and International Studies, 2012, Seven revolutions, viewed 21 June 2012, from http://csis.org/program/seven-revolutions

Cooke, P., Heidenreich, M. \& Braczyk, H.J., 2004, Regional innovation systems, Routledge, London.

Daft, R.L., 1992, Organisation theory and design, 4th edn., West Publishing, St Paul.

Dalal, S., 2008, The innovation boot camp, The Institute for Effective Innovation, Orange.

Davenport, T.H., 1993, Process innovation: Reengineering work through information technology, Harvard Business School Press, Boston.

Desrochers, P., 2001, 'Local diversity, human creativity and technological innovation', Growth and Change 32, Summer, 369-394.

Edquist, C., 1997, Systems of innovation: Technologies, institutions and organisations, Pinter, London.

Fayol, H., 1987, General and industrial management: Henri Fayol's classic, Rev. Irwin Gray, David S. Lake Publishers, Belmont.

Fonseca, J., 2002, Complexity and innovation organizations, Routledge, London.

Fornaciari, C.J \& Dean, K.L., 2001, 'Making the quantum leap: Lessons from physics on studying spirituality and religion in organizations', Journal of Organizational Change Management, 14(4), 335-351.

Galbraith, J.R., 1982, Designing complex organisations, Addison-Wesley, Reading.

Gottfredson, M. \& Aspinall, K., 2006, 'Innovation versus complexity: What is too much of a good thing?' Harvard Business Review November, 1-9.

Hamalainen, R.P. \& Saarinen, E., 2006, 'Systems intelligence: A key competence for organisational life', Reflections 7(4), 17-28.

Hartel, J., Schmidt, F. \& Keyes, L., 2003, Well-being in the workplace and its relationship with business outcomes: A review of the Gallup studies, American Psychological Association, Washington, DC.

Henderson, R.M. \& Clark, K.B., 1990, 'Architectural innovation: Reconfiguration of existing product technologies and the failure of established firms', Administrative Science Quarterly 35, 9-30. http://dx.doi.org/10.2307/2393549

Huhtala, H. \& Parzefall, M-R., 2007, 'A review of employee well-being and innovativeness: An opportunity for a mutual benefit', Creativity and
Innovation Management 16(3), 299-306. http://dx.doi.org/10.1111/j.1467Innovation Manage
8691.2007.00442.x

Johnson-Lenz, P. \& Johnson-Lenz, T., 2009, Six habits of highly resilient organizations, viewed 02 February 2010 from $\mathrm{http}: / /$ www.peopleandplace.net/ perspectives/2009/2/2/six_habits_of_highly_resilient_organizations

Kaufman, S., 1993, The origins of order, Oxford University Press, New York.

Lewin, R. \& Regine, B., 1999, The soul at work: Unleashing the power of complexity science for business success, Orion Business Books, London.

Lundvall, B.A., 1992, National systems of innovation: Towards a theory of innovation and interactive learning, Palgrave-MacMillan, London.

Macadam, C., 1996, 'Addressing the barriers of managing change', Management Development Review 9(3), 38-40.

McKelvey, B., 1999, 'Complexity theory in organisation science: Seizing the promise or becoming a fad?', Emergence 1(1), 5-32. http://dx.doi.org/10.1207/ s15327000em0101_2

McLean, L.D., 2005, 'Organizational culture's influence on creativity and innovation: A review of the literature and implications for human resource development', Advances in Developing Human Resources 7, 226-246.

Meieran, G.S., 2012, 21st century innovations, viewed 28 June 2012, from http:// www.engineeringchallenges.org/cms/7126/8275.aspx

Organisation for Economic Co-operation and Development, 2005, Os/o Manual: Guidelines for collecting and interpreting innovation data Manual: Guidelines for collecting and interpreting innovation data,
OECD, Paris, viewed n.d., from http://www.oecd.org/science/ innovationinsciencetechnologyandindustry/2367580.pdf

Pellissier, R., 2001, Searching for the quantum organisation: The IT circle of excellence, Juta, Cape Town

Pellissier, R., 2011, 'The implementation of resilience engineering to enhance organisational innovation in a complex environment', International Journal of Business and Management 6(1), 145-164.

Perrow, C., 1967, 'A framework for the comparative analysis of organizations', American Sociological Review 26, 854-866. http://dx.doi.org/10.2307/2090570

Peterson, M.W., 1999, 'Using contextual planning to transform institutions', in M. Peterson (ed.), ASHE reader on planning and institutional research, pp. 224, Pearson Custom Publishing, Needham Heights.

Porter-O'Grady, T. \& Malloch, K., 2003, Quantum leadership: A textbook of new leadership, Jones and Bartlett, Sudbury.

Puccio, G.J., Firestien, R.L., Coyle, C. \& Masucci, C., 2006, 'A review of the effectiveness of CPS training: A focus on workplace issues', Creativity and Innovation Management 15(1), 19-33. http://dx.doi.org/10.1111/j.1467-8691.2006.00366.x 
Ravichandran, T. \& Rai, A., 2000, 'Quality management in systems development: An organizational system perspective', MIS Quarterly 24(3), 381-415.

Robb, D., 2000, 'Building resilient organizations', Organization Design Practitioner 32(3), 27-32.

Roberts, E., 1999, 'Managing invention and innovation', IEEE Engineering Management Review 17, 3-13.

Rosen, R, 1991, Life Itself: A Comprehensive Inquiry into the Nature, Origin, and Fabrication of Life (Complexity in Ecological Systems), Columbia University Press, New York.

Scott, W.R., 1992, Organisations: Rational, natural and open systems, Prentice-Hall, Englewood Cliffs.

Scott, M., Gaylard, H., Wallace, S. \& Edmonds, B., 1998, 'SDML: A multi-agent language for organisational modeling', Computational \& Mathematical Organization Theory $4(1), 43-70$.

Shenk, D., 2009, Data smog: Surviving the information glut, Harper Collins e-Books. Simon, H.A., 1996, The sciences of the artificial, 3rd edn., MIT Press, Cambridge. Smith, D., 2010, Exploring Innovation, 2nd edn., McGraw-Hill Education, Berkshire.

Sousa, F., Monteiro, I. \& Pellissier, R., 2008, 'Creativity and problem solving in the development of organisational innovation', in Legardeur, J. \& De Sousa J.P. (eds.), Towards new challenges for innovative management practices, ERIMA '08 proceedings 2(1), Barcelona, Spain, 06-07 November, pp. 5-11.

Sousa, F., Pellissier, R. \& Monteiro, I., 2009a, 'Creativity and problem solving in the development of organisational innovation', Discussion Papers No. 1: Spatial and
Organisational Dynamics, Research Centre for Spatial and Organization Dynamics and University of Algarve, Algarve.

Sousa, F., Pellissier, R. \& Monteiro, I., 2009b, 'Measures of effectiveness of creative problem solving in developing team creativity', in De Boeck Supérieur (ed.) Projectics/Proyéctica/Projectique, PROJECTICS '0́9 proceedings 2009(3), BidartSan Sebastian, France, 26-27 November, pp. 41-52.
Spence, W.R., 1994, Innovation: The communication of change in ideas, practices and products, Chapman \& Hall, London.

Stacey, R.D., Griffin, D. \& Shaw, P., 2000, Complexity and management: Fad or radical challenge to systems thinking, Routledge, London.

Standish, R.K., 2008, Concept and definition of complexity, viewed n.d., from http:// arxiv.org/pdf/0805.0685.pdf

Strambach, S., 2002, 'Change in the innovation process: New knowledge production and competitive cities - The case of Stuttgart', European Planning Studies 10(2), 215-231.

Taylor, J.S., De Lourdes Machado, M. \& Peterson, M.W., 2008, Leadership and strategic management: Keys to institutional priorities and planning', European Journal of Education 43(3), 369-386. http://dx.doi.org/10.1111/j.1465-3435.2008.00363.x

Thompson J.D. \& MacMillan, C., 2010, 'Business models: Creating new markets and societal wealth', Long Range Planning 43(2-3), 291-307. http://dx.doi. org/10.1016/j.lrp.2009.11.002

Unsworth, K.L., 2005, 'Creative requirement: A neglected construct in the study of employee creativity?', Group Organisation Management 30, 541-560. http:// dx.doi.org/10.1177/1059601104267607

Weick, K., 1979, The social psychology of organisation, Random House, New York.

Wheatley, M.J., 1999, Leadership and the new science: Discovering order in a chaotic world, Berrett-Koehler, San Francisco.

Wolfe, R.A., 1994, 'Organisational innovation: Review, critique and suggested research directions', Journal of Management Studies 31, 405-431. http://dx.doi. org/10.1111/j.1467-6486.1994.tb00624.x

Zimmerman, B., Lindberg, C. \& Plsek, P., 2012, Edgeware: Lessons from complexity science for health care leaders, VHA Inc., Dallas.

Zohar, D., 1990, The quantum self: Human nature and consciousness defined by the new physics, William Morrow, New York. 